\title{
Ensinar história [entre]laçando futuros
}

\author{
Nilton Mullet Pereira' (D) \\ Carmem Zeli de Vargas Gil' \\ Fernando Seffner' (D) \\ Caroline Pacievitch'
}

RESUMO

$\mathrm{O}$ artigo analisa escritos em disciplinas de introdução à prática e estágio em um curso de licenciatura em história, em uma problematização do tempo e da temporalidade. Parte da premissa de que as questões urgentes do presente são condutoras da aprendizagem em história. Tal estratégia, decorrente da produção de planejamentos e de diários dos licenciandos, sustenta-se no tempo futuro como abertura ética da aula de história em sua relação com o mundo. Nesse sentido, foi fundamental o pensamento de Pagès como possibilidade para o planejamento de aulas de história, pautadas nas urgências do presente e de um passado que não passa e que, por isso mesmo, insiste e subsiste na forma de um acontecimento que distribui seus efeitos em um tempo não cronológico e não estabilizado.

PALAVRAS-CHAVE

ensino de história; planejamento de aulas de história; tempo presente.

'Universidade Federal do Rio Grande do Sul, Porto Alegre, RS, Brasil. 


\section{TEACHING HISTORY (INTER)LACING FUTURES}

\section{ABSTRACT}

This article analyzes writings on subjects related to the introduction to practice and internship in a History undergraduate course, based on a problematization of time and temporality. It assumes that current urgent issues lead to History learning. This strategy results from the preparation of plans and diaries by undergraduates and is sustained in the future as an ethical opening for History classes in its relationship with the world. In this scenario, Pagès's thought was fundamental as a possibility for planning History classes, based on urgencies of the present and a past that remains and, therefore, persists and survives as an event that distributes its effects since a non-chronological and unstable time.

\section{KEYWORDS}

History teaching; planning History classes; present time.

\section{ENSEÑAR HISTORIA (ENTRE)MEZCLANDO FUTUROS}

\section{RESUMEN}

El artículo analiza escritos en materias de introducción a la práctica y pasantía en un curso de licenciatura en historia, a partir de una problematización del tiempo y la temporalidad. Se parte de la premisa de que los problemas apremiantes del presente son propicios para el aprendizaje de la historia. Esta estrategia, resultante de la producción de planes y diarios por los estudiantes de pregrado, se sostiene en el tiempo futuro como la apertura ética de la clase de historia en su relación con el mundo. En este sentido, el pensamiento de Pagès fue fundamental como una posibilidad para la planificación de clases de historia, basadas en las urgencias del presente y un pasado que no pasa y, por lo tanto, insiste y subsiste en la forma de un evento que distribuye sus efectos desde un tiempo no cronológico y no estabilizado.

\section{PALABRAS CLAVE}

enseñanza de historia; planes de enseñanza en historia; tiempo presente. 


\section{ENSINAR HISTÓRIA É ENSINAR SOBRE O PASSADO?}

Poucos são os docentes ou pesquisadores do ensino de história que deixariam o tempo presente de fora de seus pensamentos e ações profissionais. Tornou-se esta uma obviedade tal que quase não se pensa sobre ela. De certo ponto de vista, isso significa a incorporação do papel do professor de história e de seu compromisso com a legislação educacional produzida após a Constituição Federal de 1988, na qual a formação para a cidadania recebe destaque. De outro ponto, essa postura significa o reconhecimento de críticas dirigidas por jovens estudantes e por nossos pares a um ensino de história tedioso, desinteressante (mesmo que não desinteressado) e memorialista que talvez (enfatizamos o talvez) fosse muito útil para a formação de certa identidade nacional, mas que rendia ao ensino de história críticas tais como as recuperadas por Elza Nadai há trinta anos (Nadai, 1992/1993). Ademais, pode isso significar o reflexo de perspectivas da teoria da história que acolhem o posicionamento ético e político dos historiadores na metodologia e na epistemologia da história.

Nossos/as alunos/as, no curso de história, estão imersos em discussões historiográficas que situam a história do tempo presente ou a história recente como um campo que resgata as subjetividades do historiador e põe em xeque as pretensões de uma história que acreditava ser possível produzir o passado separado do presente do historiador. Estão cientes, portanto, do que advertem as autoras Franco e Levín (2007) de que a história recente define-se por não só exclusivamente regras temporais, epistemológicas ou metodológicas, como também por questões que interpelam a sociedade e transformam os fatos do passado em problemas do presente. Nesse sentido, os acontecimentos traumáticos têm forte presença, mas não só. Diferentes questões convocam o educador a fazer e ensinar história em uma trama entre o que passou e o que continua do que passou. Tais discussões constituem ferramentas de análise que definem as escolhas dos futuros professores durante o planejamento, ou seja, fazem compreender as especificidades desse campo baseado em diversas formas de coetaneidade entre passado e presente; a existência de uma memória social viva do passado; a contemporaneidade entre a experiência vivida pelo historiador e o passado do qual se ocupa implica pensar o presente como uma construção histórica que tem relação com a experiência vivida pelo sujeito que conhece. Não é, portanto, como anuncia Aróstegui, a história de uma época, mas pode delimitar-se por um lapso histórico de perfil cronológico ou que tenha sua matriz estabelecida por um acontecimento decisivo: "Sin un tiempo efectivamente medido no habría posibilidad de historia” (Aróstegui, 2004, p. 57).

Para o professor em formação, compreender os debates em torno da história do presente é estar comprometido com as implicações do passado no presente, aberto aos questionamentos sobre a tarefa do historiador diante dos acontecimentos-limite. Como fazer história diante de algo tão atroz que ocorreu diante dos olhos do mundo, diante da sociedade moderna, em pleno desenvolvimento das mais finas tecnologias, que prometiam facilitar nossa vida e melhorar nossas relações uns com os outros e de todos com o mundo? É, também, exercer a docência ciente da dimensão política e ética da história, deixando-se interpelar pela pergunta: Como estudar o presente de forma que as memórias do passado ajudem a interpretar o que passa hoje? Assim, a dimensão política e ética da história recente é também uma possibilidade na 
construção de futuros. Entre o passado que estuda e o presente que vive, resta ao/a professor/a de história situar a experiência vivida no contexto histórico de forma que possa ampliar a compreensão da e abrir a vida para novas experiências, nas quais a injustiça, o racismo e a violência não existam.

No âmbito do ensino de história, a obra de Joan Pagès talvez seja um exemplo que bem ilustra a complexidade das relações entre presente, passado e futuro no campo do ensino. Em sua opinião, o ensino de história, de geografia e de ciências sociais tem a responsabilidade tanto de posicionar-se perante os problemas do tempo presente quanto de ajudar as pessoas a agir sobre eles.

Los problemas son profundos. [...] Desde mi punto de vista, los más preocupantes son los que se relacionan con el discurso del odio y el uso de la violencia, de cualquier tipo de violencia pero, en particular, la que se ejerce contra las mujeres, los niños y las niñas y los y las ancianas y contra las personas y colectivos que quieren ser diferentes. El incremento de la violencia y de actitudes sexistas, homófobas, racistas, xenófobas, intolerantes y su traducción política en Europa, en América y en prácticamente todo el mundo debería ser objeto de una enorme preocupación y debería hacernos plantear cuáles son los retos a los que deberíamos dar respuesta a través de la enseñanza de las ciencias sociales, de la geografía y de la historia y la formación de su profesorado. (Pagès, 2018, p. 19, grifo nosso)

Estabelecidos esses problemas, Pagès sustenta que

la ciudadanía democrática debería ser, sin lugar a dudas, la meta principal de una enseñanza que ha de poner énfasis en lo que nos hace humanos, en todos los derechos de todas las personas y en la dignidad humana por encima de cualquier otra cosa. (Pagès, 2018, p. 20)

A cidadania democrática é, em síntese, aquela que julga como inaceitável qualquer tipo de injustiça, fome e violência e que, paralelamente, assume que há muitos caminhos possíveis para construir sociedades não injustas. $\mathrm{O}$ ensino pautado por esses dois princípios básicos teria por responsabilidade permitir aos jovens o conhecimento sobre os caminhos percorridos pela humanidade e a possibilidade de se posicionar e de agir em relação àquilo que precisa ser mudado, a partir do estudo de problemas sociais relevantes ou de questões socialmente vivas. Ou seja, trata-se de levar as novas gerações a perceber que é possível mudar o mundo e de oferecer-lhes, de maneira instigante, os conteúdos necessários para tal (Pagès, 2018, p. 21). Os critérios para selecionar esses conteúdos - e que questionam, de uma só vez, a organização por círculos concêntricos e a organização cronológica — deveriam ser os seguintes: permitir uma visão ampla dos assuntos, incluir protagonistas diversos e estar localizados no tempo e no espaço. Do ponto de vista metodológico, é necessário estratégias para organizar e tornar complexo paulatinamente o pensamento dos estudantes (Pagès, 2018, p. 23).

Pagès inclui, por fim, a preocupação com os afetos e sentimentos na sala de aula, fechando o círculo com as demandas de um tempo presente em que a mobilização do ódio e do medo tem voltado à ordem do dia. É preciso, para além de pensar na relação presente-passado, “[...] enseñar para la utopía, es decir para 
el futuro, [lo que] puede ser una alternativa razonable a una enseñanza obsoleta y alejada de los problemas actuales de la ciudadanía" (Pagès, 2018, p. 41).

Ensinar história é, portanto, ensinar sobre os tempos? Ainda que as formas de representar o tempo, que tem tornado a sala de aula de história um lugar do "passado frio e disciplinado"(White, 2014), tenham feito coincidir história e tempo, a premissa que sustenta este artigo indica o contrário. A inserção de questões da vida pública do presente na aula de história parte do pressuposto de que tempo e história não são idênticos. Tal suposição sugere, de primeiro, que a abordagem das urgências do presente proporcionam entrar no delicado debate sobre as políticas do tempo (Ávila, 2016) em uma aula de história; de segundo, que a problematização do presente e da atualidade não indica uma submissão da aula ao presente, seja ele um "presente eterno", seja ele qualquer forma de "presentismo" (Hartog, 2013).

Pensar o tempo presente na aula de história e, de uma só vez, a cidadania e a injustiça como elementos por meio dos quais a narrativa histórica assume significado na vida das pessoas parece enviar-nos ao plano de uma problematização do tempo e das temporalidades que tem sujeitado a aula de história como lócus de um passado morto, disciplinado (White, 2014) e desinteressante. Desse modo, tornar as urgências do presente em conteúdo da aula de história e disparador da elaboração de planejamentos consiste em inserir o elemento ético no centro do debate sobre as implicações do ensino de história, o que significa elaborar uma forte crítica ao aprisionamento do tempo realizado pelo eurocentrismo, abrindo as possibilidades de pensar, medir ou representar o tempo de modos ainda não catalogados. Então, o que propomos é - uma vez desfeita a identidade entre tempo e história — deixar fluir os devires-minoritários (Deleuze e Guattari, 1997), deixar transitar em nossas salas de aula de história "o povo que falta", os povos que escaparam à narrativa histórica, uma vez que foram sempre vistos e ditos por dentro dos marcadores temporais eurocêntricos (moderno, atrasado, inovador, antiquado, evoluído...), por essa "imagem de tempo hegemônica em nossa cultura" (Pelbart, 2000, p. 129), atravessados por uma linha que dividia moralmente a modernidade (europeus) e o atraso (outros povos) (Quijano, 2005). Do mesmo modo, essa irreconciliação do tempo com o que se disse dele abre o debate histórico para temáticas que usurpam, pela força de sua relevância, o tempo sucessivo, linear e evolucionista, que criou uma distância aparentemente irreconciliável entre o passado e o presente.

Decorre dessa crítica a possibilidade de repensar o presente e suas urgências, bem como o passado que delas dizemos e abordar tanto esse passado quanto o tempo presente como coexistentes e coetâneos, o que torna, como já afirmamos, "os fatos do passado problemas do presente". Nesse sentido é que o caráter ético e o caráter estético do ensino de história apresentam-se como a forma pela qual problematizamos o presente e abrimos possibilidades de futuros. Abordar as questões relevantes da vida pública no presente, como o racismo, a violência ou o autoritarismo (tal como nos documentos que analisaremos), revela essa maneira labiríntica de pensar o tempo, fazendo coincidir passado e presente, apresentando um passado que não passa e que, por isso mesmo, insiste e subsiste na forma de um acontecimento que distribui seus efeitos em um tempo não cronológico e não estabilizado. Tudo se passa como se o tempo não se identificasse com os modos de medi-lo, representá-lo ou significá- 
-lo. Ora, se supomos que tais modos são qualidades que uma política cria, produz e impõe ao tempo, como maneiras particulares e contingentes de estabelecer-lhe os limites cronológicos, então o tempo passa a ser considerado o em si, ontológico, que, no seu recuo, se deixa capturar apenas pelas formas particulares por meio das quais estabelecemos os limites para a experiência. $\mathrm{O}$ tempo é um excesso em relação às temporalidades que criamos para dar forma a ele. São, portanto, criações humanas, produções culturais, políticas do tempo que, ao se constituírem e se estabelecerem, excluem outras temporalidades, outros modos de dar qualidades humanas ao tempo.

Esses questionamentos sobre o tempo presente na aula de história não são casuais. Eles emergiram como o fenômeno conmovedor, que, para Ana Zavala e Magdalena Scotti (2005), é a origem das investigações práticas da prática, isto é, de pesquisas feitas por professores sobre suas próprias práticas. Fomos mobilizados pelas produções de nossos alunos, futuros professores de história, em seus primeiros ensaios de criação de aulas de história, em duas disciplinas ministradas por nós: uma de caráter teórico-prático, introdutória aos estágios e ministrada em docência compartilhada por todos nós, e a disciplina de estágio em ensino fundamental. Essas produções têm sido objeto de nossos projetos de pesquisa, que se debruçam sobre o fenômeno da aula de história e da educação histórica das juventudes. A escrita deste texto é fruto dessa reflexão coletiva, que tem rendido questionamentos diversos, alguns já publicados. Em outras palavras, as reflexões aqui postas têm tempo e lugar de nascimento, crescimento e maturação. No entanto, os atores envolvidos não são apenas os autores do artigo. A natureza das disciplinas que lecionamos faz-nos atentos ao "que anda na cabeça e na boca" tanto dos estagiários quanto dos estudantes das escolas e de outras instituições onde ocorrem os estágios. A aula de história é discutida, planejada e organizada no diálogo entre os docentes orientadores e os estagiários da licenciatura em história, em escolas públicas da Região Metropolitana de Porto Alegre, em regime de complexas negociações com os desejos e vontades das culturas juvenis. Todos esses elementos modificaram-se nos últimos anos, ao incluir as demandas sociais e políticas que recaíram sobre o ensino de História ao longo do período, a isso somado visível clima de perseguição e censura causado pela atuação combinada dos movimentos "Escola sem Partido" e "Ideologia de Gênero", conforme discutido em Seffner e Picchetti (2016) e Seffner (2017).

As fontes que usamos para pensar a preocupação com o tempo presente no ensino de história praticado em nossas disciplinas por esse período foram: programas das disciplinas; planejamentos dos estagiários; diário de campo das observações e das orientações de estágio; artigos escritos ao longo desse período e que fizeram menção ao tema. Esses registros foram lidos e analisados, buscando, especificamente, a preocupação com o tempo presente na aula de história, cotejando com as problematizações teóricas que apresentamos ao início, o que se transformou em um projeto de pesquisa sobre a produção do planejamento e a aula de história, na perspectiva de pensar o presente e o futuro como elementos temporais significativos de uma aula de história. O que se discute a seguir é pequena parte desse exercício de investigação, construído em dois momentos: primeiro, situar as preocupações com o presente, examinando a ementa das disciplinas de estágio docente; e, segundo, analisar alguns planejamentos e práticas dos estagiários desafiados a pensar o tempo presente. 


\section{COMO AS PREOCUPAÇÕES COM O TEMPO PRESENTE HABITAM/HABITARAM AS DISCIPLINAS DE ESTÁGIO DOCENTE DA ÁREA DE ENSINO DE HISTÓRIA?}

Na ementa dos programas das disciplinas e nos apontamentos feitos para guiar as aulas dadas por nós, percebemos que, com reformulações na linguagem, aparecem expressões como "indagar-se sobre a pertinência dos conteúdos em História na sua conexão com as questões vividas no contemporâneo"; "elaboração do planejamento das aulas de História em sintonia com a realidade escolar contemporânea"; "atenção às questões das culturas juvenis"; "evitar o acúmulo de informações históricas que não guardam conexão com a realidade vivida pelos estudantes"; "acolhimento das demandas dos alunos"; "ênfase nos tópicos que ajudam alunos e alunas a entenderem sua realidade vivida"; "evitar que a história seja vista como ciência que se ocupa unicamente do passado"; "reflexão sobre a realidade vivida pelos alunos para melhor desenhar o planejamento das aulas de ensino de História”; "observação prévia ao estágio da escola e das condições de ensino, e conversa com os alunos da classe em que se dará a docência, para colher elementos que ajudem a pensar o planejamento em sintonia com essa realidade"; "capacidade em estabelecer conexões entre os tópicos da História ensinada e os temas da realidade vivida pelos alunos"; "desenvolver um ensino de História que permita compreender as ações humanas no tempo e no espaço, fornecendo elementos para pensar os problemas contemporâneos"; "desenvolver estratégias para produção de aprendizagens significativas em História, entendidas como aquelas em que as lições do passado iluminam questões do presente e fazem diferença na vida dos alunos, modificando seus modos de ser e pensar"; "evitar a tentação de querer ensinar ‘ todo’ o conhecimento histórico de determinado período, preferindo a seleção de tópicos que possam fazer diferença na vida do tempo presente dos alunos". Tais questões, para além de constarem nos programas, foram objeto de artigos escritos à época.

Esses questionamentos implicam repensar um arcabouço de conhecimentos escolares que possuem uma longa tradição no ensino de História e, em alguma medida, romper com essa tradição. Se a História é construção, narrativa, interpretação do passado a partir das questões que nos colocamos no presente, a aprendizagem na escola estará atenta aos modos de produção de leituras do passado e de construção de argumentos que explicitem uma narrativa coerente, plausível, situada no tempo e no espaço de modo pertinente. A elaboração de narrativas do passado a partir de questões do presente supõe o uso de instrumentos, procedimentos e vocabulário específicos. (Seffner e Stephanou, 2005, p. 176)

A preocupação com o presente era difusa e servia muitas vezes para combater certo viés enciclopedista do ensino de história. Atentar para o presente dos alunos poderia ser um critério para deixar de lado partes do passado que, naquele momento, não estavam ajudando a "entender" o presente. Ao longo do tempo, a preocupação com as questões do tempo presente ampliou-se ao pensar o planejamento das aulas de história, 
e, com isso, incorporou conceitos e temas de outras ciências humanas, como a sociologia, a ciência política e a geografia, dando lugar, em parte, ao chamado ensino de temas sensíveis, questões socialmente vivas ou questões controversas (Pereira e Seffner,2018).

\section{POR MEIO DE QUAIS MODOS AS PREOCUPAÇÕES COM O TEMPO PRESENTE EXPRESSARAM-SE NAS AULAS DOS ESTAGIÁRIOS?}

Quanto aos modos pelos quais tal preocupação com o presente se expressou, identificamos duas estratégias pedagógicas bem distintas. Ao ler os diários de campo da observação das aulas e dos encontros de orientação com os/as estagiários/as, o presente não era exatamente o ponto de partida para a aula de história. A ênfase estava posta em um bom ensino de um tópico do passado, denso e rico em informações e conceitos, que encerrava com a clássica pergunta: $\mathrm{O}$ que isso tem a dizer sobre os dias de hoje? $\mathrm{A}$ preocupação com o presente aparecia então após o estudo do passado. No Quadro 1, parte de um relato do Diário de Campo de Observação das Aulas evidencia isso:

\section{Quadro 1 - Diário de Campo de Observação das Aulas de 1996.}

[...] A turma é de oitavo ano, estamos no final do ano letivo, é uma escola pública de região muito pobre na cidade e todos os indicadores mostram que a maior parte do alunado não vai seguir os estudos para o segundo grau. [...] Com isso na cabeça, a estagiária, muito articulada e preocupada com a produção das suas aulas, pensou em dedicar esse momento final do ano letivo para tentar "dar sentido" ao que tinha sido aprendido em História [...]. Foi colado na parede um enorme mapa mundial, com a divisão política de alguns países, desenhado em papel pardo, com os contornos em cores fortes de países ou regiões selecionadas. Um grupo de alunos tinha feito isso nas aulas anteriores, colocando nomes de países e regiões. [...] Posto o mapa, duplas de alunos colaram, em alguns países e regiões papéis com dois tipos de informação. Um deles eram recortes de manchetes de jornais, em geral com conflitos, guerras e coisas do tipo, acontecidas naquele país ou região e retiradas de jornais das últimas semanas. [...] Outras duplas haviam escrito, em pequenos papéis, informações históricas estudadas acerca desses mesmos países ou regiões ao longo dos anos nas aulas de História. Nos dois casos, matérias de jornal de hoje e informações sobre o passado, também se colaram gravuras. Por exemplo, foi colado no Egito (um dos países selecionados), tanto uma gravura das pirâmides como uma foto da cidade do Cairo hoje. [...] A atividade de colagem foi encerrada, e a estagiária então conduziu o debate, que foi feito a partir de uma pergunta [...]. Ela disse: "vamos ver como o que vocês aprenderam nas aulas de História ajuda a entender o que se passa hoje nestes países”. Essa pergunta é uma variação do que já escutei de outros estagiários, que quando concluem um tópico de estudos perguntam "o que isso nos ajuda para entender a vida hoje em dia nessa região"? Embora os esforços e a boa vontade da estagiária, a atividade ficou um tanto longe do que ela pretendia. Algumas modalidades de conclusões se destacaram. A primeira delas foi algo como "hoje é assim porque no passado tal coisa aconteceu", o que foi assumido com certo ar de fatalismo. [...] Então os alunos estabeleceram uma conexão direta entre exploração no passado e miséria no presente, que se não deixa de estar um tanto correta, traz uma matriz de explicação histórica bastante mecanicista. Além disso, por desconhecimento da história africana, muitos concluíram também que a África sempre havia sido pobre, e que tinha ficado agora mais pobre ainda. Mas o caso do Egito implicou divergências. Eles disseram que o Egito tinha sido rico antigamente, mas hoje era uma ditadura e um país pobre. Não foi possível ir além, por falta mesmo de elementos históricos. Na região da América Latina a tônica foi a mesma [...]. Para a Europa a confusão foi ainda maior: havia fotos de palácios e lindas gravuras medievais, e para os dias de hoje fotos de Paris, Londres e Berlim. A Europa sempre tinha sido rica e agora seguia sendo rica. Enfim, uma atividade que implicou tal grau de coleta de informações deu origem a um debate bastante pobre, o que frustrou a estagiária, mas permitiu interessantes reflexões.

Fonte: acervo da disciplina introdução à prática e estágio em história (Faculdade de Educação/ Universidade Federal do Rio Grande do Sul - FACED/UFRGS). 
A segunda estratégia pedagógica de preocupação com o presente deu-se com duas ênfases principais: o presente é tudo (é início, meio e fim das aulas de história, especialmente quando elas são dadas para alunos das classes populares) ou o presente é terreno do qual se coletam pistas para estudar o passado. No primeiro caso, a aula de história corre o risco de certo jornalismo contemporâneo; e, no segundo, temos abertura para o estudo de questões sensíveis do presente, que convive de modo difícil com a narrativa histórica tradicional, por vezes lembrando mais uma aula de antropologia ou sociologia do que de história (Quadros 2 e 3 ).

\section{Quadro 2 - Diário de Campo das sessões de Orientação de Planejamento, 1998.}

A sessão de orientação para o planejamento das aulas foi difícil hoje. Os dois estagiários estão em escola de grande porte em bairro próximo ao centro da cidade, com turmas de primeiro ano do ensino médio, mesma professora regente, turno da noite. As duas classes são compostas de alunos trabalhadores. [...] Os dois estagiários são fortemente vinculados a certas posições teóricas e políticas que falam da revolução feita pelos pobres e trabalhadores para barrar o capitalismo. Ficaram então um tanto decepcionados ao verificar que o tema das aulas que irão lecionar nestes primeiros anos do ensino médio é História Antiga [...]. Acresce a isso o fato de que a professora regente, segundo eles, lhes deu grande liberdade para escolherem os conteúdos a serem lecionados. Estamos em período eleitoral, com a possibilidade de reeleição aprovada no ano passado. [...] O somatório de todos estes fatores resultou numa proposta de programa para as aulas de História que era de acompanhamento das eleições presidenciais e dos demais cargos, combinada com uma avaliação do governo de Fernando Henrique Cardoso [...]. A História Antiga havia saído completamente do planejamento, substituída pelo panorama de atualidades eleitorais. Questionados por mim sobre isso, de imediato retrucaram que para os alunos que iriam dar aulas, todos pobres e trabalhadores, não fazia sentido ficar dando conteúdos de caldeus, assírios, persas, egípcios, fenícios, com tanta coisa acontecendo na vida política nacional. Além do mais, ao conversar com as turmas, haviam percebido que, por serem alunos um pouco mais velhos, vários deles já estavam aptos a votar [...]. Depois de muita negociação, chegamos a um acordo, em que as aulas teriam uma sessão de acompanhamento da vida nacional (o que chamamos de observatório do presente), organizada com os alunos e a partir de seus interesses na vida política (e não a partir dos interesses estritos dos estagiários [...]), e conteúdo de História Antiga em conexão com a realidade dos países que ora existem naquelas regiões. [...]

Fonte: acervo da disciplina introdução à prática e estágio em história (Faculdade de Educação/ Universidade Federal do Rio Grande do Sul — FACED/UFRGS).

\section{Quadro 3 - Diário de Campo das sessões de Orientação de Planejamento, 2017.}

Ótima conversa hoje de orientação do planejamento das aulas com duas estagiárias, que vão trabalhar em regime de docência compartilhada no ensino fundamental, oitavo ano. As duas são feministas e apresentaram uma proposta de aulas que tinha como fio condutor na história do Brasil e da Europa as questões das mulheres e das relações de gênero. Trouxeram abundante material didático, ótimas ideias, planejamento feito da primeira à última aula. A classe em que vão lecionar é composta, segundo elas, por grande maioria de meninas, escola da zona leste da cidade, que no ensino médio é uma tradicional escola normal. [...] Mas conversamos sobre esses recortes tão profundos, que elegem uma linha específica, e como isso dialoga, ou pode dialogar, com um relato mais geral de cada período histórico. Difícil chegar a um consenso ou meio-termo nisso.

Fonte: acervo da disciplina introdução à prática e estágio em história (Faculdade de Educação/ Universidade Federal do Rio Grande do Sul — FACED/UFRGS). 
Este curto histórico ajuda a situar a preocupação com as questões do tempo presente nas aulas de ensino de história. Nos últimos anos, com a presença cada vez mais numerosa e ativa de alunos e alunas que ingressaram na universidade pelo sistema de reserva de vagas e com a presença mais numerosa de mulheres no curso de licenciatura em história, apareceu uma variante da preocupação com as questões do tempo presente. Ela é dada pela problematização da figura do estagiário, que se coloca como um docente marcado pela posição social, geração, gênero, aspectos raciais, pertencimento de classe, trajetória de escolarização, orientação sexual, convicções políticas, crença religiosa, histórico familiar e projetos de futuro. É cada vez mais comum que os estagiários, ao apresentarem seus planos de ensino e suas ideias para o estágio, façam-no problematizando sua própria vida e trajetória pessoal e política. Isso traz com vigor certa centralidade para seu corpo, um elemento do presente simbolizado pela cor da pele e pelo conjunto de marcas que nos constitui. Estudos sobre corpos de professores são recorrentes na literatura em educação.

Nós, professoras e professores, raramente falamos do prazer de Eros ou do erótico em nossas salas de aula. Treinadas no contexto filosófico do dualismo metafísico ocidental, muitas de nós aceitamos a noção de que há uma separação entre o corpo e a mente. Ao acreditar nisso os indivíduos entram na sala de aula para ensinar como se apenas a mente estivesse presente, não o corpo. [...] O que se faz com o corpo na sala de aula? [...] Entrando na sala de aula, determinadas a anular o corpo e a nos entregar por inteiro à mente, nós demonstramos através de nossos seres o quão profundamente aceitamos o pressuposto de que a paixão não tem lugar na sala de aula. [...] Para restaurar a paixão pela sala de aula ou para estimulá-la na sala de aula, onde ela nunca esteve, nós, professores e professoras, devemos descobrir novamente o lugar de Eros dentro de nós próprios e juntos permitir que a mente e o corpo sintam e conheçam o desejo. (hooks, 2001, p. 115 e 123)

\section{O QUE MUDOU EM 2018?}

No primeiro semestre de 2018, a disciplina de introdução ao estágio, planejada e ministrada em docência compartilhada dos autores deste artigo, como já mencionado, propôs um desafio intenso em torno das conexões entre o ensino de história e o tempo presente. Em pequenos grupos, os/as estudantes foram convidados/as a construir uma sequência didática (incluindo um material didático autoral) inspirados no texto de Joan Pagès (2015), La educación política y la enseñanza de la actualidad en una sociedad democrática, escolhendo uma das proposições indicadas pelo autor para ensinar história com problemas do presente. São elas: atualidade como pretexto, atualidade como presente, atualidade como comparação, atualidade como problema e atualidade como perspectiva. No texto, Pagès discute a necessidade de relacionar a formação política dos jovens com o ensino da atualidade, contribuindo para implicá-los nos problemas da vida pública. Trata-se de construir um projeto pedagógico de escola, cuja práxis cotidiana se assente no trabalho cooperativo, na construção de conhecimento e menos na transmissão repetitiva ou em conteúdos: “[...] han de estar 
centrados en problemas políticos que sean fácilmente identificables como tales y sobre los que se pueda intervenir" (Pagès, 2015, p. 24). Assim, o autor indica a importância do currículo se constituir, também, da abordagem dos problemas do presente, que dizem respeito aos debates públicos e políticos da atualidade. No final do semestre, realizamos um seminário para debater cada planejamento. No Quadro 4, apresentamos oito desses trabalhos, destacando o enfoque sobre o presente, os conceitos, os objetivos e a metodologia.

Quadro 4 - Planejamentos em 2018/1.

\begin{tabular}{|c|c|c|c|c|}
\hline & Enfoque & Conceitos & Objetivos & Referências \\
\hline 1 & $\begin{array}{l}\text { Atualidade } \\
\text { como } \\
\text { perspectiva }\end{array}$ & $\begin{array}{l}\text { Imperialismo } \\
\text { Etnocentrismo } \\
\text { Racismo }\end{array}$ & $\begin{array}{c}\text { Compreender os conceitos, romper } \\
\text { com a ideia de história ligada apenas } \\
\text { ao passado e aplicar os conceitos na } \\
\text { atualidade. }\end{array}$ & $\begin{array}{l}\text { Edward Said } \\
\text { Paulo Freire } \\
\text { Nilton Pereira } \\
\text { Lana Siman e } \\
\text { Araci Coelho }\end{array}$ \\
\hline 2 & $\begin{array}{l}\text { Atualidade } \\
\text { como } \\
\text { comparação }\end{array}$ & $\begin{array}{c}\text { Violência } \\
\text { Autoritarismo } \\
\text { Direitos Humanos }\end{array}$ & $\begin{array}{c}\text { Promover o trânsito presente-passado- } \\
\text { presente por meio de casos de violação } \\
\text { de Direitos Humanos na ditadura } \\
\text { militar. } \\
\text { Participar, discutir com argumentos e } \\
\text { agir criticamente. }\end{array}$ & $\begin{array}{l}\text { Rafael Saddi } \\
\text { Sonia Miranda } \\
\text { Marizete Lucini } \\
\text { Mével e Tutiaux- } \\
\quad \text { Guillon }\end{array}$ \\
\hline 3 & $\begin{array}{l}\text { Atualidade } \\
\text { como } \\
\text { presente }\end{array}$ & Violência policial & $\begin{array}{c}\text { Ler e analisar fontes de forma } \\
\text { crítica e refletir sobre as diferenças e } \\
\text { semelhanças entre a ditadura militar e a } \\
\text { violência policial atual. }\end{array}$ & $\begin{array}{l}\text { Alessandra } \\
\text { Gasparotto } \\
\text { Enrique Padrós } \\
\text { Suzana Zaslavsky }\end{array}$ \\
\hline 4 & $\begin{array}{l}\text { Atualidade } \\
\text { como } \\
\text { problema }\end{array}$ & $\begin{array}{l}\text { Propaganda } \\
\text { Monarquia } \\
\text { República }\end{array}$ & $\begin{array}{c}\text { Perceber mudanças e permanências nos } \\
\text { conceitos de monarquia e democracia, } \\
\text { problematizando essa percepção em } \\
\text { propagandas e memes. }\end{array}$ & $\begin{array}{l}\text { Luis Fernando } \\
\text { Cerri } \\
\text { Joan Pagès }\end{array}$ \\
\hline 5 & $\begin{array}{l}\text { Atualidade } \\
\text { como } \\
\text { comparação }\end{array}$ & $\begin{array}{l}\text { Terrorismo de Estado } \\
\text { Resistência } \\
\text { Arte política }\end{array}$ & $\begin{array}{c}\text { Debater censura, pensando em } \\
\text { continuidades e descontinuidades entre o } \\
\text { presente e o período da ditadura militar. }\end{array}$ & $\begin{array}{l}\text { Michel Foucault } \\
\text { Enrique Padrós }\end{array}$ \\
\hline 6 & $\begin{array}{l}\text { Atualidade } \\
\text { como } \\
\text { comparação }\end{array}$ & $\begin{array}{l}\text { Ditadura civil-militar } \\
\text { Intervenção militar }\end{array}$ & $\begin{array}{l}\text { Conhecer o período da ditadura militar } \\
\text { e suas contradições, pensando nos } \\
\text { apelos recentes por intervenção militar. }\end{array}$ & $\begin{array}{l}\text { Carla Rodeghero } \\
\text { Joan Pagès }\end{array}$ \\
\hline 7 & $\begin{array}{l}\text { Atualidade } \\
\text { como } \\
\text { pretexto }\end{array}$ & Imigração & $\begin{array}{c}\text { Conhecer aspectos diversos sobre a } \\
\text { imigração europeia para o Sul do Brasil. }\end{array}$ & $\begin{array}{l}\text { Joan Pagès } \\
\text { Lana Siman e } \\
\text { Araci Coelho } \\
\text { Miriam M. Leite }\end{array}$ \\
\hline 8 & $\begin{array}{l}\text { Atualidade } \\
\text { como } \\
\text { pretexto }\end{array}$ & $\begin{array}{l}\text { Revolta dos Malês } \\
\text { Período regencial }\end{array}$ & $\begin{array}{l}\text { Conhecer informações históricas } \\
\text { sobre a Revolta dos Malês e o período } \\
\text { regencial. Relacionar com problemas } \\
\text { atuais a com base em obras de arte. }\end{array}$ & $\begin{array}{l}\text { Silvia Petersen e } \\
\text { Bárbara Lovato } \\
\text { João José Reis }\end{array}$ \\
\hline
\end{tabular}

Fonte: acervo da disciplina introdução à prática e estágio em história (Faculdade de Educação/ Universidade Federal do Rio Grande do Sul - FACED/UFRGS). 
Nos planejamentos em que localizamos as conexões temporais mais complexas, notamos alguns pontos em comum: todos se propuseram a explorar a bibliografia oferecida na disciplina e a combiná-la com seus referenciais próprios, criaram materiais ou estratégias didáticas originais e criativas e rechaçaram a dicotomia entre aula expositiva tradicional e aula "diferente". Essa reflexão aprofundada estimulou a criação de materiais didáticos e/ou estratégias de aula que podem mobilizar questionamentos e aprofundar os conceitos escolhidos em cada planejamento. Esses materiais didáticos tiveram, ainda, a função de romper com a separação entre a apresentação do conteúdo e as atividades, permitindo fluidez e orientando o raciocínio dos jovens para além da simples aquisição de informações sobre o passado. Podemos concluir, preliminarmente, que essas produções expõem o problema do tempo de modo exacerbado na aula de história - cada uma à sua maneira. Se o presente parece assumir o papel principal, em verdade são os futuros, o horizonte, que sobrevoa cada uma das aulas. Tratou-se, de maneira deliberada e interessada, de criar sequências didáticas nas quais as questões que envolvem a vida pública no presente se constituam em conteúdo do currículo de história. Eis, portanto, que o presente como disparador para criação de sequências didáticas é revelador de uma profunda problematização do tempo e da temporalidade.

\section{PLANEJANDO O FUTURO DESDE O PRESENTE}

Para finalizar o ciclo de análises, retomaremos dois exemplos de planejamentos e de aulas de história que foram efetivamente concretizados em situação de estágio. Consideramos que essas duas produções problematizam o tempo em suas formas representativas eurocêntricas e seus modos particulares de propor e estabelecer relações com o passado. A perspectiva que apresentamos nesse momento parte de dois argumentos centrais: o primeiro diz respeito ao repensar as fronteiras entre passado e presente, pondo no locus do debate da aula de história a existência de passados que não passam e que coexistem com o presente; o segundo refere-se à ideia de que o planejamento propõe que o estudo da história desde o presente indica e remete não ao passado ou ao próprio presente, mas ao futuro, o qual consiste em um estado de abertura que possibilita a criação de novas experiências históricas ainda não catalogadas e definidas nos limites do presente. Tudo se passa como se o futuro fosse uma construção que se dá pela aprendizagem da ampla experiência histórica do passado e da crítica ao presente, base na qual novos futuros poderão ser construídos.

O primeiro planejamento foi elaborado pelas alunas Luana de Lima da Silva, Maria Cristina Estima da Silveira, Priscila de Souza Santos e Vitória Guedes Duarte. Trata-se do planejamento 1 apresentado no Quadro 4 e envolvia a realização de três aulas, focadas na aquisição, construção e utilização de quatro conceitos históricos: imperialismo, resistência, colonização e etnocentrismo. A estratégia pedagógica utilizada foi partir, na primeira aula, de uma atividade que permitisse responder a seguinte questão: há fenômenos culturais, políticos e sociais na realidade vivida pelos alunos que podem ser classificados como modalidades de imperialismo, resistência, colonização e etnocentrismo? A partir dessa exploração, a proposição era construir esses quatro conceitos, examinando as articulações entre 
eles e seu potencial explicativo. Nas duas aulas seguintes, armados dessas ferramentas conceituais, os alunos iriam explorar situações do século XIX em que tais conceitos pudessem ajudar a entender as relações históricas entre algumas regiões. A atividade foi originalmente prevista para alunos do ensino médio. No semestre seguinte, duas das alunas autoras do planejamento, Priscila e Vitória, realizaram estágio em uma turma de sexto ano em uma escola de classe média baixa na Zona Leste da cidade. A primeira aula, com duração de dois períodos, foi assistida pelo professor supervisor, que posteriormente debateu com as estagiárias suas observações. $\mathrm{O}$ planejamento feito pelas duas alunas se inspirou naquele do semestre anterior, mas com modificações importantes, como a descrição a seguir permite ver, e com adaptações para os temas em estudo no programa do ano indicado.

Contando com 23 alunos, a classe foi acolhida na sala de aula e levada para a sala de vídeo. A atividade dizia respeito aos conceitos de etnocentrismo e imperialismo e estava ambientada no Egito Antigo. Na segunda parte, o planejamento previa, com o uso de gravuras, mostrar como as mulheres foram apagadas ou tiveram seu papel diminuído na história oficial do Egito. Organizaram-se então em cinco grupos. Foi solicitado pelas estagiárias que, no primeiro momento, apenas escutassem as músicas propostas, sem comentar entre si. A primeira música foi a de um rapper egípcio Zap Tharwat (em colaboração com Amina Khalil), "Nour”, em árabe. Essa música provocou curiosidade e tentativas de adivinhação da língua. O estilo rap foi identificado e causou surpresa a alternância entre uma voz masculina e uma feminina. A música brasileira foi identificada por algumas alunas, tratava-se de "Dona de mim", da cantora Iza. De modo sintomático, os meninos da turma não reconheceram letra e melodia dessa música. Uma rodada de conversa mostrou que a classe não sabia a autoria da música em árabe, nem do que ela tratava, mas fizeram especulações envolvendo elementos do Oriente, falando em deserto. Citaram como possibilidade que a língua fosse o árabe e se puseram a imaginar com quais roupas estariam vestidos, dizendo que deviam ser terroristas, que era a música de um ritual religioso ou que "estavam todos drogados, pelo jeito de cantar". A seguir, o clipe da música em árabe foi projetado, agora com som e imagem. O debate após a projeção, com mediação das estagiárias, permitiu que a classe identificasse que se tratava de um homem jovem - tido pelas meninas como muito bonito e pelos meninos como um sujeito com cara de terrorista - que se encarregava de cuidar de seus filhos, alimentando, levando à escola, colocando para dormir e dialogando musicalmente com uma mulher, que poderia ser sua esposa ou companheira. Em algumas cenas, as tarefas domésticas eram igualmente divididas entre o homem e a mulher. O videoclipe projetado tinha legenda em inglês, o que permitiu perceber que o diálogo entre o homem e a mulher falava em equidade de gênero, mas essa informação não era acessível aos alunos. Ao contrário das especulações acerca do deserto, o videoclipe se passava em uma cidade e foram apontados tanto elementos coincidentes com o modo de vida dos alunos quanto elementos diversos, no que se refere ao aspecto das ruas, transporte coletivo, interior do apartamento onde viviam as personagens, roupas, comidas consumidas, carros que apareciam nas ruas etc. De modo unânime, a classe afirmou que não tinha sido possível identificar o tema da música e que era uma surpresa que se tratasse da história de um homem cuidando dos filhos, repartindo as tarefas com a mulher. Aqui, o conceito de etnocentrismo 
foi construído, e algumas anotações foram feitas pelos alunos nos grupos, a partir da pergunta: Por que ficamos surpresos ao ver um homem e uma mulher repartindo as tarefas domésticas, em um clipe de música do Oriente? A seguir foi projetado o videoclipe da música brasileira. Algumas meninas cantaram junto, os meninos se mantiveram mais calados, alguns até mesmo um tanto constrangidos, pois a cantora faz afirmações fortes.

O debate a seguir foi dominado por elas, que demonstraram conhecer a cantora e citaram muitos casos no bairro, em que mulheres tinham de trabalhar e cuidar sozinhas dos seus filhos. Uma menina afirmou: "A mulher que é dona de si é malfalada nessa vila". Em contrapartida, alguns meninos citaram casos, mais raros, nos quais o homem é quem cuidava de tudo em relação aos filhos, na tentativa de mostrar que isso também acontecia ali. De qualquer modo, a centralidade do debate envolveu o protagonismo feminino, conceito que estava previsto no planejamento. Em particular, uma frase do videoclipe levantou polêmica: "Já não me importa a sua opinião/ O seu conceito não altera minha visão/ Foi tanto sim que agora eu digo não". Alguns meninos usaram a tática do deboche em relação às meninas e à própria atividade, improvisando uma estrofe ao som da música que dizia "elas antes só diziam sim, agora querem dizer não, mas é sim, sim, sim”, o que elevou os ânimos. A aula aconteceu em uma quinta-feira pela manhã, entre duas datas significativas: no sábado anterior (29 de setembro de 2018), aconteceram as manifestações feministas conhecidas como "Ele não", em referência ao repúdio de grupos de mulheres ao candidato à presidência Jair Bolsonaro; e o primeiro turno das eleições presidenciais iria acontecer em 7 de outubro, logo no fim de semana seguinte.

Essa situação, não prevista no planejamento, fez com que o debate incorporasse posições partidárias. Um menino negro, com argumentação clara e vocabulário bem cuidado, afirmou enfaticamente que "a mulher não cuida só da casa, ela pode fazer outras coisas". Em resposta, um menino branco disse simplesmente: "Eu apoio o Bolsonaro". Algumas meninas e o menino negro que havia feito a primeira afirmação disseram que Bolsonaro era um candidato machista e racista. $\mathrm{O}$ menino branco afirmou então: "Ele pode ser machista e racista, mas ele não está preso". O menino negro respondeu: "A prisão do Lula não foi legal". O branco disse: "Ele está preso porque ele roubou", e o menino negro encerrou a discussão dizendo: "Ele roubou pouquinho, mas ele ajudou os pobres no seu governo", o que recebeu certo apoio geral da classe. As estagiárias aproveitaram para encerrar a questão e encaminhar o debate para o que lhes interessava, que era trazer à tona o cuidado de um homem com os filhos no vídeo do Oriente e a mulher negra dona de si no vídeo do Ocidente. Vários alunos e alunas se manifestaram, dizendo que de fato eles imaginavam que "lá na Arábia" os homens eram todos terroristas, nunca cuidavam dos filhos, e as mulheres eram completamente submissas, não saíam de casa nunca e se vestiam da cabeça aos pés de burca. Os meninos tiveram que reconhecer, pela pressão das meninas, que mulheres donas de si não eram bem vistas por eles. Um menino com modos afeminados, sentado em um grupo com quatro meninas, aproveitou para dizer que também os meninos gays eram hostilizados e retomou o assunto das eleições dizendo: "Eu não vou votar no Bolsonaro", ao que alguns retrucaram: "Tu não vota mesmo, porque tu é 'de menor". 
As estagiárias fizeram então os alunos anotarem no caderno algumas conclusões desse primeiro momento, insistindo na questão conceitual. Em seguida, projetaram diversos slides mostrando mulheres politicamente poderosas no Egito Antigo, caso da rainha Hatshepsut, importante faraó do Egito. Os alunos se lembraram de Cleópatra e de Nefertiti, e slides delas foram mostrados. No entanto, o que mais chamou a atenção da classe foram slides e informações sobre grupos de mulheres com muita autonomia no Egito Antigo, como carpideiras, prostitutas, donas de pequenos comércios, viúvas ricas etc. Discutiu-se que essas informações não eram esperadas para aqueles povos do Oriente, e muito menos no Egito Antigo. Um slide sobre o direito ao divórcio no Egito Antigo provocou debates, por não ser também esperado. Novamente o conceito de etnocentrismo foi usado e importantes elementos do conceito de imperialismo entraram na pauta, com a classe concordando que tudo que sabiam sobre "os árabes" era de fontes ocidentais e, além do mais, norte-americanas. Todos riram quando uma menina disse que nenhum deles tinha visitado o Egito na vida e nunca iriam visitar mesmo. Esse ponto levou ao debate se apenas se poderia saber "exatamente" como era a vida lá indo até aquele local. Todavia as estagiárias lembraram o videoclipe como uma fonte de produção local, importante para cotejar com as fontes que eles haviam citado.

Depois dessa atividade, as estagiárias mostraram gravuras apresentando sobre como os egípcios haviam desenvolvido a produção de papel com papiro. Novamente alguns comentaram que achavam que o papel era uma invenção da Europa, e não dos árabes. Os grupos receberam uma atividade de recorte e colagem: produção de papiros para escrita de frases. A técnica de produção de papiros, envolvendo cola, gaze, borra de café e algumas folhas de papel, ocupou todo o período seguinte e foi muito atraente. Ao longo da produção, os grupos discutiram acerca de imagens e frases que seriam colocadas no papiro e que mostrassem o protagonismo feminino, com traços da produção artística egípcia. $\mathrm{O}$ debate acerca das frases e imagens foi grande e ocorreu enquanto se produziam os papiros. Tudo foi colocado para secar em um cordão esticado no fundo da sala. Em relato posterior, as estagiárias narraram que a maioria da turma optou por desenhar Cleópatra ou Nefertiti, com poucos grupos dando espaço para as profissões e ocupações de menor visibilidade que haviam sido mostradas, como prostitutas, carpideiras etc. Os papiros produzidos foram mostrados, permitindo ver o esforço em desenhar de acordo com os traços artísticos do Egito Antigo. No verso do papiro, estava escrito o título da pintura e o motivo de sua escolha. Para finalizar, os alunos buscaram encontrar, em livros didáticos trazidos da biblioteca, informações sobre as mulheres comuns no Egito Antigo e nada localizaram, e sim apenas referências a mulheres famosas, como Nefertiti, Cleópatra e, mais raramente, Hatshepsut.

A atividade propiciou um questionamento sobre práticas sociais na atualidade e o protagonismo feminino, em conexão com etnocentrismo e imperialismo, mas de modo por vezes "confuso" aos olhos de um historiador profissional, basicamente porque todo o estudo foi atravessado por questões do cotidiano cultural e social dos alunos. O objetivo foi pensar a historicidade do presente. Causou espanto nos alunos saberem do protagonismo feminino em uma sociedade tão recuada no tempo e ainda mais por estar situada no que eles genericamente designaram várias vezes como "a Arábia”. O que se verificou foi como conceitos históricos permitem operar com realidades determinadas e identificar passados que insistem e persistem, em um processo 
de coexistência com o presente. Nesse sentido, o presente tornou-se o disparador que demonstrou desacomodação e angústia em relação à atualidade. A noção de protagonismo feminino dialogou de modo intenso com aquela de etnocentrismo, e o passado constituiu-se em uma experiência que se confunde com o presente do qual ele hoje é passado. Foi desse modo que pensar de uma só vez o presente e o passado criou uma cesura no tempo, permitindo um belo exercício de imaginação de futuros não descritos ou prescritos, nos quais o etnocentrismo, o imperialismo e o machismo não existem.

O segundo planejamento foi uma produção dos estudantes Bruno Corrales e Misael dos Santos Beskow (2018), que abordou o tema do Brasil Império por meio de uma estratégia pedagógica que considerou o presente como disparador para pensar os passados vivos (Pereira e Seffner, 2018), como foi o caso da escravidão no Brasil. O conteúdo a ser estudado consistia em aspectos socioeconômicos do período, considerando os diversos grupos sociais implicados nos processos econômicos e o tema da escravidão, levando em conta "as estruturas de poder envolvidas, métodos de obtenção de alforrias, resistência escrava (quilombos, fugas e conflitos com senhores), situação da população negra livre e liberta durante todo o período imperial"(Corrales e Beskow, 2018, p. 1). A aula constituiu-se, em seu início, como um plano do qual emergem situações provocantes que criam acontecimentos, implicando relações inusitadas, problematizações incertas e criações estranhas ao modelo de vínculos temporais familiares ao eurocentrismo.É assim que o presente entrou nessa aula: como puro estranhamento. $O$ presente e suas urgências, em vez de apresentarem-se como o que define o porvir ou o que sugere um limite às relações possíveis com o passado, tornam-se o próprio tempo, ainda não demarcado pelo padrão de possibilidades de sua interpretação. Assim, ele provoca uma angústia que se inicia com o professor e passa aos alunos, tornando-se o próprio tempo da aula. Ou seja, a angústia com o presente torna-se a justa abertura que permite ir ao passado para problematizar o presente e aprender com o passado. Foi assim que a aula se iniciou com um clichê enunciado pelo então presidente eleito do Brasil: “Tudo é 'coitadismo', diz Bolsonaro sobre negros, mulheres e nordestinos" (Veja, 2018 apud Corrales e Beskow, 2018).

O lançamento desse clichê para iniciar uma aula de história sobre o passado imperial brasileiro foi como criar um fosso por onde desceram todos os modelos já vistos e experienciados sobre o que consiste em aprender sobre o passado que aqueles alunos conheciam. As forças continuaram a cruzar o que já era, àquela altura, um acontecimento, a sala de aula de Bruno e Misael. E eles perguntam aos estudantes: "Será que é 'coitadismo mesmo?". Uma pergunta aparentemente simples é justamente o que angustia e abre de uma só vez para o campo da imaginação, para o campo da problematização e, por fim, para o campo da criação. Esse tipo de pergunta faz tremer o senso comum, o que parece não só inquestionável na experiência histórica dos estudantes, mas também prepara um não lugar em que todas as crenças podem, num piscar de olhos, ser desfeitas, e é exatamente aí, numa espécie de gênese da criação, que o passado aparece, ao mesmo tempo que o presente e o futuro. Misael e Bruno afirmam:

a ideia é discutir com os alunos se os movimentos de luta das populações que sofrem discriminação podem ser considerados puramente como "vitimismo" ou se decorrem de uma reação a um processo maior em que esses preconceitos fo- 
ram produzidos e construídos historicamente na sociedade brasileira ao longo dos últimos dois séculos. (Corrales e Beskow, 2018, p. 3)

Essa aula da turma 82 foi notável, pois se propôs abordar temáticas urgentes que ultrapassam os limites temporais e estudar os conceitos de "escravidão, resistência, discriminação, racismo e desigualdade social”. Conforme Bruno e Misael, a aula dividiu-se em três momentos: o primeiro passou pela leitura do artigo $3^{\circ} \mathrm{da}$ Constituição Federal de 1988, iniciando-se uma breve discussão sobre como os preconceitos de origem, raça, sexo, cor e outras formas de discriminação estão presentes na nossa sociedade hoje em dia, estabelecendo uma relação com discursos discriminatórios presentes na mídia — nesse momento foram exibidas algumas manchetes de jornais, trazendo o que pensa o presidente recém-eleito sobre essas questões; no segundo momento, foi passado aos alunos dados sobre a população negra, em uma tentativa de pensar historicamente o racismo e o preconceito; o terceiro momento implicou a exibição do DVD contido na caixa pedagógica "África no Arquivo", elaborada pelo Arquivo Público do Estado do Rio Grande do Sul (APERS).

$\mathrm{O}$ mais impressionante e mais difícil foi a inserção nessa aula das questões referentes à recente eleição presidencial, particularmente o depoimento do então candidato Jair Bolsonaro, descrito anteriormente. Entretanto, a abordagem do tema da escravidão e do racismo, a partir da menção aos ditos do agora presidente da República, permitiu acessar uma realidade social que não pode ser vista mediante uma leitura fria do passado ou como uma descrição desinteressada de um presente aceitável e considerado normal. $\mathrm{O}$ recurso a pensar historicamente o racismo e a escravidão foi rigoroso, do ponto de vista conceitual, e necessário, do ponto de vista ético, pois essa abertura e simpatia, criadas pelo disparador que dissipou as crenças, os clichês e os modelos enraizados sobre as relações entre passado, presente e futuro, permitiu uma aula em que os problemas do presente (desigualdade, movimentos de luta, resistências) misturaram-se às questões do passado (escravidão, protagonismo dos escravizados, aspectos econômicos do Império) por meio de um estudo com documentos - cartas de alforria, testamento de ex-escravos, inventários de senhorios, processos-crime e documento de compra e venda —, possibilitando imaginar futuros, abrir um campo de estranhamento para a criação de novas experiências, ao passo que revisamos e repensamos nossas relações no presente.

\section{DE PASSADOS, DE PRESENTES E DE FUTUROS VIVE A AULA DE HISTÓRIA}

Pensar em um passado distante de um presente que lhe é tecnológico e moralmente superior e na de um futuro que promete uma redenção é um modo muito particular de uma política do tempo que é excludente, violenta e genocida. Trata-se de uma maneira eurocêntrica de pensar a temporalidade, de dar sentido ao tempo, de medir, representar e ter experiência. Assim, a identificação entre o tempo e a história não é outra coisa senão um modo muito sofisticado de tornar uma forma específica de medir e representar o tempo universal e necessária. Essa temporalidade quadripartite, contínua, sucessiva e evolucionista é uma maneira criada pela modernidade europeia de dar qualidade ao tempo. Sua arma principal 
foi a de fazer coincidir tempo e temporalidade, para esconder seu caráter particular e político. Abordar as urgências do presente significa, primeiro, supor que não há identidade entre tempo e temporalidade e entre tempo e história - o que vai permitir tornar as aulas espaços disponíveis para a abertura a quaisquer formas de medir, representar ou experienciar o tempo; segundo, supõe pensar o tempo não mais por dentro dessa temporalidade eurocentrada, sucessiva e linear, desfazendo a "solidariedade entre tempo e história", tal como afirma Pelbart (2004, p. 39).

Trata-se, no limite, de desfazer a solidariedade entre Tempo e História, com todas as implicações éticas, políticas e estratégicas de uma tal ambição. Ao pensar as multiplicidades substantivas e os processos que nela operam, aí desentocando temporalidades as mais inusitadas, no arco que vai do Intempestivo até o Acontecimento, não terá Deleuze dado voz àqueles que, como diz ele num eco benjaminiano, "a História não leva em conta”? Não se trata, evidentemente, só dos oprimidos ou das minorias, embora sempre se trate deles também, mas dos devires-minoritários de todos e de cada um: não exatamente o povo, mas "o povo que falta", o povo por vir.

É assim que a tematização do presente se constitui num processo pelo qual a história problematiza o presente e abre-se aos futuros. Tudo se passa como se, ao problematizar o racismo, o etnocentrismo ou o lugar das mulheres como um passado que não passa e que coexiste com o presente, a aula de história pudesse abrir o passado para o escrutínio da experiência. Trata-se não apenas de pensar a historicidade das práticas racistas e do caráter estrutural do racismo em nossa sociedade, mas também de aprender sobre experiências humanas do passado em que o racismo não teve lugar, em que os problemas tiveram modos diferentes de resolução que ainda não conhecemos. Ora, dessa maneira, criamos uma indiscernibilidade do próprio passado com o futuro, já que o futuro deixa de ser o desdobramento da historicidade do presente e se torna a abertura imaginária de novas possibilidades de vida, nesse caso sem o racismo e sem a injustiça. Eis o elemento ético do ensino de história, que consiste no que Pagès (2018, p. 41) chama de "enseñar para la utopía", ensinar para o futuro.

É desse modo que os planejamentos que apresentamos e as aulas deles decorrentes estilhaçaram o tempo: jogando com as temporalidades; fazendo com que um acontecimento qualquer, abordado como uma urgência do presente, pudesse se comunicar com outros presentes, como outros passados e com outros mundos, colocando em xeque não só o malfadado movimento contínuo da linha que tem colonizado nossos modos de pensar e de dar aulas de história, como também a possibilidade de uma descrição de um passado já sem efeito para a vida. Estivemos, neste artigo, procurando por outros tempos, outras temporalidades: bifurcadas, coexistentes, coetâneas, turbilhonares. Ficamos mergulhados na potência da pergunta de Pelbart (2000, p. 218): Quais seriam esses outros tempos? Esses "que nossas máquinas de amar, sentir, perceber, sonhar, imaginar, criam incessantemente, e que nem de longe poderiam entrar sob a rubrica disciplinada de um tempo da história e de seu sentido excessivamente orientado?”.

A consequência disso tudo foram planejamentos e aulas de história que se voltaram para a imaginação, para a utopia e para o futuro - no sentido de uma potência aberta à criação de novas relações e de novos mundos. Talvez o que tenhamos 
feito nesses anos foi perseguir incessantemente os indícios que nossas "máquinas de imaginar" deixavam pelo caminho, tenuemente sugerindo que existem muitas outras vidas, muitos outros tempos, muitas outras maneiras de se criar relações com o passado e com o futuro, desde a angústia que nos constitui no presente.

\section{REFERÊNCIAS}

ARÓSTEGUI, J. La historia vivida. Sobre la historia del presente. Madrid: Alianza, 2004. p. 19-61.

ÁVILA, A. L. Povoando o presente de fantasmas: feridas históricas, passados presente e as políticas do tempo de uma disciplina. Revista Expedições: Teoria da História \& Historiografia, Góias, ano 7, n. 2, p. 189-209, ago./dez. 2016.

CORRALES, B.; BESKOW, M. S. Relatório de estágio. Licenciatura em História. Disciplina: Estágio de Docência em História - Ensino Fundamental. Porto Alegre: UFRGS, 2018.

DELEUZE, G.; GUATTARI, F. Mil platôs. São Paulo: Editora 34, 1997.

FRANCO, M.; LEVÍN, F. El pasado cercano en clave historiográfica. In: FRANCO, M.; LEVÍN, F. (comps.). Historia reciente. Perspectivas y desafíos para un campo en construcción. Buenos Aires: Paidós, 2007. p. 31-66.

HARTOG, F. Regimes de historicidade: presentismo e experiências do tempo. Belo Horizonte: Autêntica, 2013.

HOOKS, B. Eros, erotismo e o processo pedagógico. In: LOURO, G. L. (org.). O corpoeducado: pedagogias da sexualidade. Belo Horizonte: Autêntica, 2001. p. 113-123.

MARQUES, A. Dona de mim. Intérprete: Iza. Rio de Janeiro: Warner Music Brasil. 2018. 1 CD. Streaming. Download digital.

NADAI, E. O ensino de história no Brasil: trajetória e perspectiva. Revista Brasileira de História, São Paulo, v. 13, n. 25/26, p. 143-162, set. 1992/ago. 1993.

PAGÈS, J. La educación política y la enseñanza de la actualidad en una sociedad democrática. Educação em Foco, v. 19, n. 3, p. 17-37, nov. 2014/fev. 2015.

PAGÈS, J. Los retos de la enseñanza de las ciencias sociales, la geografía y la historia: Qué profesorado, qué ciudadanía, qué futuro? Reseñas, Córdoba, n. 16, p. 15-46, 2018. PELBART, P.P.A vertigem por um fio: políticas da subjetividade contemporânea. São Paulo: Iluminuras; FAPESP, 2000.

PELBART, P. P. O tempo não-reconcliliado: imagens do tempo em Deleuze. São Paulo: Perspectiva, 2004.

PEREIRA, N. M.; SEFFNER, F. Ensino de história: passados vivos e educação em questões sensíveis. Revista História Hoje, São Paulo, v. 7, n. 13, p. 14-33, 2018. Disponível em: https://rhhj.anpuh.org/RHHJ/article/view/427. Acesso em: 30 mar. 2019. https://doi.org/10.20949/rhhj.v7i13.427

QUIJANO, A.A colonialidade do saber: eurocentrismo e ciências sociais. Perspectivas latino-americanas. Buenos Aires: CLACSO, 2005. 
SEFFNER, F. Escola pública e função docente: pluralismo democrático, história e liberdade de ensinar. In: MACHADO, A. R. A.; TOLEDO, M. R. A. (orgs.). Golpes na história e na escola: o Brasil e a América Latina nos séculos XX e XXI. São Paulo: Cortez Editora, 2017. p. 199-216.

SEFFNER, F.; PICCHETTI, Y. P. A quem tudo quer saber, nada se lhe diz: uma educação sem gênero e sem sexualidade é desejável? Reflexão e Ação, v. 24,n. 1, p. 61-81, 2016. Disponível em: https://online.unisc.br/seer/index.php/reflex/article/view/6986. Acesso em: 30 mar. 2019. http://dx.doi.org/10.17058/rea.v24i1.6986

SEFFNER, F.; STEPHANOU, M. De novo a mesma história? O que ensinar e aprender nas aulas de História? Perguntas que não querem calar. In: FILIPOUSKI, A. M. R.; MARCHI, D. M.; SCHÄFER, N. O. (orgs.). Teorias e fazeres na escola em mudança. Porto Alegre: Editora da UFRGS, 2005. p. 173-179.

THARWAT, Z. Nour. Intérpretes: Zap Tharwat, Amina Khalil \& Sary Hany. Cairo, Egypt: AXEER Studio. 2018. 1 CD. Streaming. Download digital.

WHITE, H. The practical past. Evanston: Northwestern University Press, 2014. ZAVALA, A.; SCOTTI, M. (comps.). Historias de la enseñanza de la historia. Relatos que son... teorías. Montevideo: CLAEH, 2005.

\section{SOBRE OS AUTORES}

Nilton Mullet Pereira é doutor em educação pela Universidade Federal do Rio Grande do Sul (UFRGS). Professor na mesma instituição. E-mail: niltonmp.pead@gmail.com

Carmem Zeli de Vargas Gil é doutora em educação pela Universidade Federal do Rio Grande do Sul (UFRGS). Professora na mesma instituição. E-mail: carmemz.gil@gmail.com

Fernando Seffner é doutor em educação pela Universidade Federal do Rio Grande do Sul (UFRGS). Professor na mesma instituição.

E-mail: fernandoseffner@gmail.com

Caroline Pacievitch é doutora em educação pela Universidade Estadual de Campinas (UNICAMP). Professora na Universidade Federal do Rio Grande do Sul (UFRGS).

E-mail: caroline.pacievitch@ufrgs.br

Recebido em 4 de abril de 2019 Aprovado em 6 de agosto de 2019 